\title{
MATHEMATICAL APPARATUS USED IN "METHOD OF MODELS” FOR THE STUDY OF SLIDER-CRANK MECHANISM (RRRP)
}

\author{
Roumen Roussev \\ Faculty of Technics and Technologies of Yambol, Trakia University of Stara Zagora, Bulgaria \\ Faculty of Engineering, South-West University "Neofit Rilski", Blagoevgrad, Bulgaria \\ e-mail: roussev_r@abv.bg
}

\begin{abstract}
The method of models" is a graphical method for determining kinematic characteristic of links and points of polycontoured mechanism. It allows solving the problem only for the desired link or point. For this purpose must find their images in "secondary" and "tertiary" model of mechanism. In present paper mathematical apparatus, replacing graphical work with analytical calculations is proposed, to analyze slider-crank mechanism (RRRP).
\end{abstract}

Keywords: method of models, kinematic characteristics, slider-crank mechanism, mathematical apparatus.

\section{INTRODUCTION}

Method of models is proposed by Piperkov [1] and writes up by Tenchev [2]. Through it can be determined kinematic characteristics of random links and points on links of polycontoured mechanism without calculate it for previous ones. Only need to determine displacement function- mist be drawn a mechanism for chosen value of the input parameter, which is assumed to be "primary model". Rules are defined, which is carried out graphic representation of "secondary model" (for determining velocities) and "tertiary model " (for determining accelerations) of mechanism. Advantage of this method is that it can obtain correct results for trigonometric functions for angles $\varphi=k . \pi / 2(k=1,2, \ldots)$. The indefiniteness of arcos functions is being avoided. The disadvantage of this method is great graphics work. Usually this method is used to analyze 12 positions of the mechanism or to clarify "conflict" positions obtained by analytical methods.

Most often polycontoured mechanisms are constructed from elementary four-linkage mechanisms, sequent connected. The slider-crank mechanism (RRRP) is one of many used in practice.

In this work mathematical apparatus is available for determining the coordinates of the characteristic points of the slider-crank mechanism in its models without graphic representation. This enables research to be conducted for any number of positions of the mechanism.

\section{NATURE OF “METHOD OF MODELS” FOR SLIDER-CRANK MECHANISM (RRRP)}

Mechanism is built for the desired position. The centre of the model has been selected, as it is the axis of rotation of input link (for RRRP) - point $\mathrm{O}$ (picture below)

\subsection{Secondary model}

Assume, that input link (crank 1 ) has angular velocity $\omega_{1}$ and angular acceleration $\varepsilon_{1}$. 1'. Input link of mechanism 1 and its secondary image $1^{\prime}$ coincide, i.e. $1 \equiv 1^{\prime}$ and $A \equiv A^{\prime}$ '. IRTIIE Vol. 4, No. 3, 2016 ISSN 1314-8788 (print), ISSN 1314-8796 (online), doi: 10.15547/artte.2016.03.003 


\section{ARITIE}

Ipplied Reseirrches in Technics, Technologies and Bducition Journal of the Faculty of Technics and Technologies, Trakia University https://sites.google.com/a/trakia-uni.bg/artte/

2'. The secondary image of the link that carried out rectilinear translation (slider 3 ) on the stationary link (carriage), is a point lying on the line that passes through the center point $O$ and is perpendicular to the direction of sliding.

$3^{\prime}$. If points $A$ and $B$ lying on the link, that performs plane motion (rocker 2), and if image $A^{\prime}$ of point $A$ is known, then secondary image $B^{\prime}$ of point $B$ locates on line, which passes through $A^{\prime}$ and is parallel to line $A B$. Points $A^{\prime}$ and $B^{\prime}$ determine the position of secondary image of the rocker 2. Velocity $V_{B}=\omega_{1} . O B^{\prime}$ of point $B$ is perpendicular to segment $O B^{\prime}$ with direction corresponding of $\omega_{1}$ relative to the center $O$. The magnitude of the angular velocity of the rocker $A B$ is $\omega_{A B}=\frac{A^{\prime} B^{\prime}}{A B} . \omega_{1}$. If directed segments $A B$ and $A^{\prime} B^{\prime}$ are unidirectional, then angular velocity $\omega_{A B}$ has direction of $\omega_{1}$. If they are not, angular velocity $\omega_{A B}$ has opposite direction of $\omega_{1}$.

Secondary image $C^{\prime}$ of third point $C$ of the rocker $A B$ is determined through triangle $A^{\prime} B^{\prime} C^{\prime}$, which is similar and equally oriented with triangle $A B C$. Velocity of point $C$ is: $V_{C}=\omega_{1} . O C^{\prime}$. Velocity of point $C$ is perpendicular to segment $O C^{\prime}$ with direction corresponding of $\omega_{1}$ relative to the center $O$.

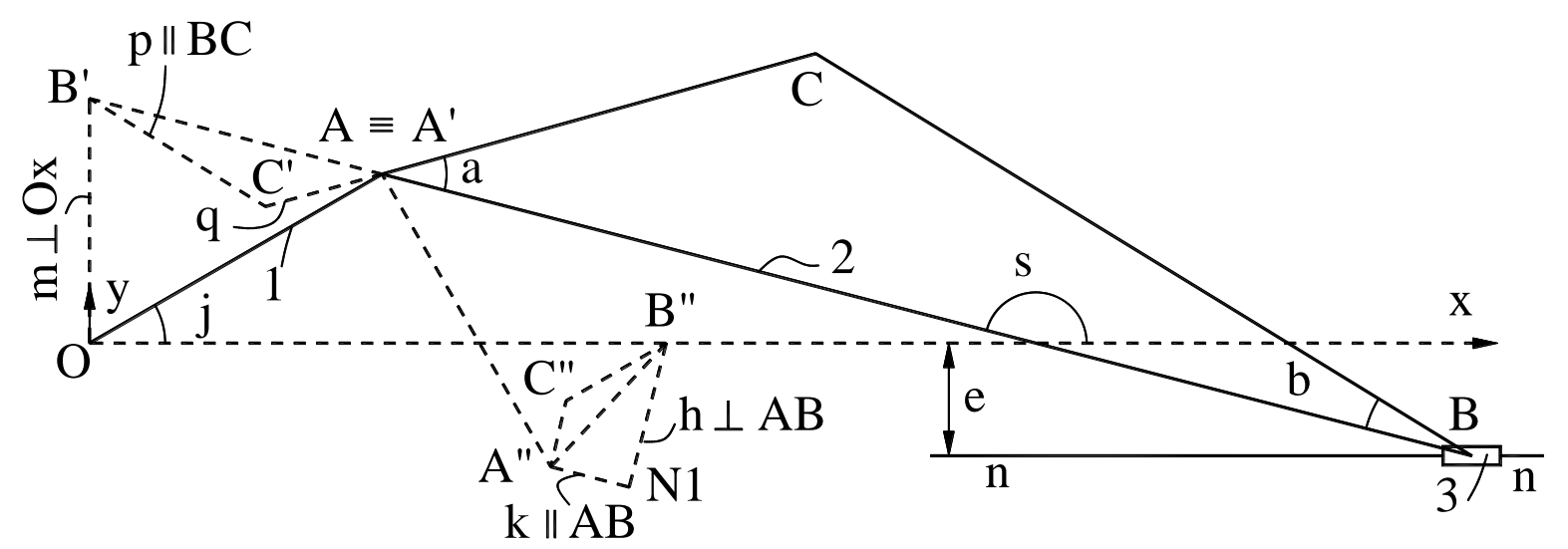

Figure 1. Graphic constructions for Secondary and Tertiary model

\subsection{Tertiary model}

1". If the primary link 1 has angular velocity $\omega_{1}=$ const $\left(\varepsilon_{1}=0\right)$, then link 1 and its tertiary image 1 " coincide, i.e. $1 \equiv 1^{\prime \prime}$ и $A \equiv A^{\prime \prime}$. The points and $A^{\prime \prime}$ determine tertiary image of input link in the tertiary model of the mechanism. If $\varepsilon_{1} \neq 0$ input link 1 and its tertiary image 1 " do not match. Image $A$ " of point $A$ is shifted perpendicularly to the segment $O A$. The magnitude of this displacement is: $A A^{\prime \prime}=\frac{\varepsilon_{1}}{\omega_{1}^{2}} . O A$, but the direction is opposite to the acceleration $\varepsilon_{1}$. The points $O$ and $A^{\prime \prime}$ determine position of tertiary image of the crank1. Acceleration of point $A$ is directed from $A^{\prime \prime}$ to $O$ with magnitude $a_{A}=\omega_{1}^{2} . O A^{\prime \prime}$. 


\section{ART'TE $Y$}

Ipplied Resseirlores in Technics, Technologies and Educration Journal of the Faculty of Technics and Technologies, Trakia University https://sites.google.com/a/trakia-uni.bg/artte/

2". The tertiary image of the link, which performs translation (slider 3 ) on the motionless link (carriage), is a point, which lies on a line passing trough the center $O$ and is parallel to the direction of sliding.

3". Points $A$ and $B$ located on the rocker which performs plain motion. If the tertiary image $A "$ of point $A$ of the rocker is known, then tertiary image $B^{\prime \prime}$ of point $B$ lies on lineq which is perpendicular to segment $A B$ at a distance $A^{\prime \prime} N_{1}$ from the image $A^{\prime \prime}$. The segment $A^{\prime \prime} N_{1}$ is determined by formula $A^{\prime \prime} N_{1}=\frac{\left(A^{\prime} B^{\prime}\right)^{2}}{A B}$. The direction from $A^{\prime \prime}$ to $N_{1}$ corresponds to the direction from $A$ to $B$. The points $A^{\prime \prime}$ and $B$ " determine position of tertiary image of the rocker in tertiary model of mechanism. Acceleration $\overrightarrow{a_{B}}$ in the tertiary model has direction from $B^{\prime \prime}$ to $O$ with magnitude $a_{B}=\omega_{1}^{2} . O B^{\prime \prime}$. If the segment $B^{\prime \prime} N_{1}$ is considers as a vector $\overrightarrow{B^{\prime \prime} N_{1}}$ and observes rotation of segment $A^{\prime \prime} B^{\prime \prime}$ on it about point $A$ ", then it is the direction of angular acceleration $\varepsilon_{A B}$ of the rocker. The magnitude of this acceleration is $\varepsilon_{A B}=\frac{B^{\prime \prime} N_{1}}{A B} \cdot \omega_{1}^{2}$.

Tertiary image $C$ " of third point $C$ of the rocker is obtained through triangle $A$ " $B$ " $C$ ", which is similar and equally oriented with triangle $A B C$. The acceleration of point $C$ has direction from $C$ " to $O$ with magnitude $a_{C}=\omega_{1}^{2} . O C^{\prime \prime}$.

\subsection{Graphic constructions}

a. Primary model: The mechanism is built for the desired position in scale $1: 1$ (Picture above). Coordinate axis Ox is chosen parallel to the direction of sliding $n-n$.

b. Secondary model:The line $m \perp O x$ is plotted through point $O$; segment $A B$ is extended to its intersection with $m$; Intersection point is point $B^{\prime}$; The line $p \| B C$ is constructed trough point $B^{\prime}$, as trough point $A$ line $q$ (segment $A C$ extension); line $q$ and line $p$ do intersect at point $C^{\prime}$.

c. Tertiary model: segment $A A^{\prime \prime} \perp O A$ is plotted; line $k \| A B$ is plotted trough point $A$ "and segment $A^{\prime \prime} N_{1}$ is noted. Through point $N_{1}$ the line $h \perp A B$ is plotted; line $h$ intersect coordinate axis $O x$ at point $B$ " which is tertiary image of point $B$; Triangle $A " B$ " $C$ ", is built which is similar to triangle $A B C$.

\section{MATHEMATICAL APPARATUS FOR DETERMINING CHARACTERISTIC POINTS OF THE MECHANISM}

From the primary model displacement function $x_{B}=x_{B}(\varphi)$ and $\sigma=\sigma(\varphi)$ is determined. Coordinates of the characteristic points of the mechanism are:

Point $A: x_{A}=O A \cdot \cos \varphi \quad y_{A}=O A \cdot \sin \varphi$

Point $B: x_{B}=O A \cdot \cos \varphi+A B \cdot \cos \sigma \quad y_{B}=e$

Point $C: x_{C}=O A \cdot \cos \varphi+A C \cdot \cos (\alpha+\sigma) \quad y_{C}=O A \cdot \sin \varphi+A C \cdot \sin (\alpha+\sigma)$

\subsection{Secondary model}

- Coordinates of p. A': $x_{A^{\prime}}=x_{A} \quad y_{A^{\prime}}=y_{A}$

- Slope of the lines:

IRTIIE Vol. 4, No. 3, 2016 ISSN 1314-8788 (print), ISSN 1314-8796 (online), doi: 10.15547/artte.2016.03.003 


\section{IRTTIE} Ipplied Researreches in Technics, Technologies and Eductation Journal of the Faculty of Technics and Technologies, Trakia University https://sites.google.com/a/trakia-uni.bg/artte/

$$
A B \rightarrow K_{A B}=\frac{y_{B}-y_{A}}{x_{B}-x_{A}} \quad O A \rightarrow K_{O A}=\frac{y_{A}}{x_{A}} \quad A C \rightarrow K_{A C}=\frac{y_{C}-y_{A}}{x_{C}-x_{A}} \quad B C \rightarrow K_{B C}=\frac{y_{C}-y_{B}}{x_{C}-x_{B}}
$$

- Coordinates of the intersection point between the rocker $A B$ and coordinate axis $O x$ :

$x_{P}=x_{A}-\frac{y_{A}}{K_{A B}} y_{P}=0$

- Coordinates of point $\mathrm{B}^{\prime}: y_{B^{\prime}}=x_{P} \cdot \tan (-\sigma) \quad x_{B^{\prime}}=0$

- Coordinates of point $C^{\prime}$ :

$$
x_{C^{\prime}}=\frac{K_{A C} \cdot x_{A^{\prime}}-K_{B C} \cdot x_{B^{\prime}}+y_{B^{\prime}}-y_{A^{\prime}}}{K_{A C}-K_{B C}} y_{C^{\prime}}=y_{B^{\prime}}+K_{B C} \cdot\left(x_{C^{\prime}}-x_{B^{\prime}}\right)
$$

- Length of the segment $O C^{\prime}: O C^{\prime}=\sqrt{x_{C^{\prime}}^{2}+y_{C^{\prime}}^{2}}$

\subsection{Tertiary model}

- Length of the segment $A A^{\prime \prime}: A A^{\prime \prime}=\frac{\varepsilon_{1}}{\omega_{1}^{2}} \cdot O A$

- Coordinates of point $A^{\prime \prime}$ :

$$
x_{A^{\prime \prime}}=x_{A}+A A^{\prime \prime} \cdot \cos \left(\frac{\pi}{2}-\varphi\right) y_{A^{\prime \prime}}=y_{A}+A A^{\prime \prime} \cdot \sin \left(\frac{\pi}{2}-\varphi\right)
$$

- Length of the segment $A^{\prime} B^{\prime}: \quad A^{\prime} B^{\prime}=\sqrt{\left(x_{A^{\prime}}-x_{B^{\prime}}\right)^{2}+\left(y_{A^{\prime}}-y_{B^{\prime}}\right)}$

- Length of the segment $A^{\prime \prime} N_{1}: A^{\prime \prime} N_{1}=\frac{A^{\prime} B^{\prime}}{A B}$

- Coordinates of point $N_{1}: \quad x_{N_{1}}=x_{A^{\prime \prime}}+A^{\prime \prime} N_{1} \cdot \cos \sigma \quad y_{N_{1}}=y_{A^{\prime \prime}}+A^{\prime \prime} N_{1} \cdot \sin \sigma$

- Slope of the line: $K_{N_{1} B^{\prime \prime}}=\frac{1}{K_{A B}}$

- Coordinates of point. $B^{\prime \prime}: \quad x_{B^{\prime \prime}}=x_{N_{1}}+\frac{y_{N_{1}}}{K_{N_{1} B^{\prime \prime}}} \quad y_{B^{\prime \prime}}=0$

- Slope of the lines: $A^{\prime \prime} B^{\prime \prime} \rightarrow K_{A^{\prime \prime} B^{\prime \prime}}=\frac{y_{A^{\prime \prime}}}{x_{A^{\prime \prime}}-x_{B^{\prime \prime}}}$ 


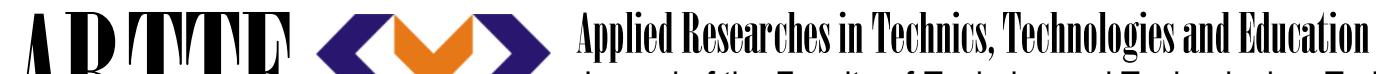 Journal of the Faculty of Technics and Technologies, Trakia University https://sites.google.com/a/trakia-uni.bg/artte/}

$$
A^{\prime \prime} C^{\prime \prime} \rightarrow K_{A^{\prime \prime} C^{\prime \prime}}=\frac{K_{A^{\prime \prime} B^{\prime \prime}}+\tan (\alpha)}{1-K_{A^{\prime \prime} B^{n}} \cdot \tan (\alpha)} ; B^{\prime \prime} C^{\prime \prime} \rightarrow K_{B^{\prime \prime} C^{\prime \prime}}=\frac{K_{A^{\prime \prime} B^{\prime \prime}}-\tan (\beta)}{1+K_{A^{\prime \prime} B^{\prime \prime}} \cdot \tan (\beta)}
$$

- Coordinates of point $C^{\prime \prime}$ :

$$
x_{C^{n}}=\frac{K_{A^{n} C^{n}} \cdot x_{A^{n}}-K_{B^{n} C^{n}} \cdot x_{B^{n}}-y_{A^{n}}}{K_{A^{\prime \prime} C^{n}}-K_{B^{n} C^{n}}} y_{C^{n}}=K_{B^{n} C^{n}} \cdot\left(x_{C^{\prime \prime}}-x_{B^{n}}\right)
$$

- Length of the segment $O C^{\prime \prime}: \quad O C^{\prime \prime}=\sqrt{x_{C^{\prime \prime}}^{2}+y_{C^{\prime \prime}}^{2}}$

With so designate coordinates of the points and length of the sections are calculated kinematic characteristics of any link and point of the mechanism.

\section{CONCLUSIONS}

This article provides mathematical apparatus for determination of kinematic characteristics of links and points on them of the slider-crank mechanism. Apparatus is based on the "method of models", retaining its advantages and avoids the extensive graphic work. Presented equations are simple and can be implemented in a computer program. Mathematical apparatus allows studying the mechanism for a desired number of positions.

\section{REFERENCES}

[1] Piperkov D. Secondary modeling in theoretical mechanics, Ph.D. Dissertation, TU Sofia, 1987.

[2] Tenchev Vasko. A small treatise of velocities and accelerations of planar linkages (second and third-level models), Sofia, 2009. 